\title{
Hand Hygiene Compliance among Healthcare Workers in Public-Sector Rural Hospitals in Benin
}

\author{
Dégbey $\mathrm{C}^{* 1,2}$, Glèlè Ahanhanzo $\mathrm{Y}^{1}$, Kakikatsoma TK${ }^{1}$, Ouendo $\mathrm{EM}^{1}$ and Makoutode $\mathrm{M}^{1}$
}

${ }^{1}$ Regional Institute of Public Health, University of Abomey-Calavi, Ouidah, Benin

${ }^{2}$ University Hospital Hygiene Clinic, National University Hospital Center Hubert Koutoukou MAGA, Cotonou, Benin

*Corresponding author: Dégbey C, Regional Institute of Public Health, University of Abomey-Calavi, Ouidah, Benin, Tél. 0022995960541; E-mail: comlancy@yahoo.fr

Citation: Dégbey C, Glèlè Ahanhanzo Y, Kakikatsoma TK, Ouendo EM, Makoutode M (2019) Hand Hygiene Compliance among Healthcare Workers in Public-Sector Rural Hospitals in Benin. J Public Health Hygiene Safety 1(1): 104. doi: 10.15744/2767-8792.1.104

Received Date: November 07, 2019 Accepted Date: December 18, 2019 Published Date: December 20, 2019

\begin{abstract}
Background: To identify the factors associated with hand hygiene compliance among healthcare workers.

Methods: It was a cross-sectional, descriptive and analytical study conducted in the nine (09) pavilions of Aplahoue District Hospital (Benin). The choice was exhaustive because of the small number of employees. The techniques used for data collection consisted of a survey questionnaire and direct observation when providing health care or services. Comparisons of proportions were made using the chi-square test. To search for associated factors, a univariate analysis of the data by simple linear regression was performed using Fisher's statistical test with a $\mathrm{p}$ value considered significant at a $5 \%$ threshold.
\end{abstract}

Results: The overall compliance rate for hand hygiene was $12.15 \%$. Factors associated with compliance rate of hand hygiene were knowledge of hospital-acquired infections from basic training (coefficient $=8.86$ and p-value $=0.000$ ), knowledge of hand hygiene in hospital setting from basic training (coefficient $=8.25$ and $\mathrm{p}$-value $=0.001$ ), soap allergies (coefficient $=-5.46$ and $\mathrm{p}$-value $=0.041$ ), wearing short-sleeved scrubs (coefficient $=9.82$ and $p$-value $=0.011$ ) and the professional category ( $\mathrm{p}$-value $<0.05$ ). Among healthcare professionals, $76.27 \%$ have a moderate level of knowledge about hand hygiene; $62.71 \%$ know the main mode of cross-transmission of germs between patients in a care facility and $93.22 \%$ know all the components of hand hygiene.

Conclusion: This study allowed us to identify the factors that need to be tackled in order to raise the overall compliance rate for hand hygiene, which is low in the Aplahoue's hospital.

Keywords: Risk Factors; Compliance; Hand Hygiene; Benin

\section{Introduction}

Hand hygiene is a global challenge, particularly in hospital settings for the safety of the patients and the healthcare workers. While caring for patients, healthcare workers' hands are gradually colonised by potentially pathogenic germs. If hand hygiene is not practiced, the longer the care lasts, the greater the contamination and the higher the associated potential risk to the patient's safety as regards hospital-acquired infections in particular, and healthcare-associated infections more generally [1]. Studies conducted in Europe and the United States between 2005 and 2006 revealed that the frequency of healthcare-associated infections varied between 5 and 15\% for hospital inpatients. This frequency stood at between 9 and $37 \%$ in patients admitted to intensive care units, with crude death rates of 12 to 80\% [2]. In Morocco, a 2007 study by El Rhazi et al. on the prevalence and risk factors of hospitalacquired infections in the CHU Hassan II hospital in Fès showed a hospital-acquired infection rate of 6.7\% [3]. In Benin, the study conducted by Biaou in 2011 on the prevalence of surgical site infections in the visceral surgery department of the National University Hospital Center Hubert Koutoukou Maga (CNHU-HKM) in Cotonou, along with the study conducted by Dégbey et al. in 2012 on the quality of the medical and technical equipment used in operating theatres to prevent healthcare-associated infections in the CNHU-HKM in Cotonou, showed hospital-acquired infection rates of $6.3 \%$ and 6.17\% respectively [4,5].

Hand hygiene is the first line of defence against hospital-acquired infections, both historically and in terms of efficacy. In Vienna, in 1845, Ignace Semmelweis, a Hungarian obstetrician, demonstrated the impact of doctors' hand hygiene on neonatal and maternal mortality; the mortality rate among newborns and mothers dropped from $12.4 \%$ to $1.3 \%$. Between 1975 and June 2008 , at least 40 studies demonstrated a link between poor hand hygiene practices and the onset of healthcare-associated infections [6]. 
Healthcare workers therefore need to improve their hand hygiene in order to reduce the prevalence of healthcare-associated infections. To effectively achieve this, an understanding of the context is required along with an analysis of the factors behind the current situation. This study aims to examine the factors associated with hand hygiene compliance among healthcare workers in a rural district hospital in Benin.

\section{Methods}

\section{Setting}

This study was conducted in the hospital in Aplahoué health district in the department of Kouffo in Benin. It is a district referral hospital that covers an essentially rural population of 250,000. The hospital has the following healthcare departments: emergency and intensive care department, maternity department, general medicine department, ophthalmology department, surgical department, physiotherapy department, operating theatres, a laboratory and the radiology department.

\section{Design}

The study was a cross-sectional descriptive and analytical study conducted in 2017.

\section{Participants}

The primary targets were healthcare workers carrying out healthcare activities in the hospital's departments. A non-probability sampling method was used with an exhaustive technique. The sample comprised 59 subjects, broken down as follows: four (04) doctors, twenty (20) nurses, four (04) midwives, five (05) biomedical technicians, one (01) anaesthetist nurse and twenty-five (25) auxiliary nurses. The latter are an occupational category that is not trained in a professional school but which supports healthcare providers in their day-to-day activities.

Laboratory technicians in the performance of their duties of service (blood, vaginal, throat, blood culture and others) should perform hand hygiene (simple hand washing, hygienic hand washing and friction hands) to not transmit to patients infections associated with care and services.

\section{Data Collection Techniques, Tools and Measures}

The techniques used for data collection were a survey questionnaire and direct observation during the provision of healthcare or services. The collection tools developed and used were a questionnaire and an observation chart. To assess the knowledge of those surveyed we used the WHO questionnaire on hand hygiene for healthcare workers [1]. This questionnaire has 11 questions with 36 possible correct answers. The questions are multiple-choice questions (MCQ); for each question there are a series of answers from which the healthcare worker chooses the one or ones they think correct. A score of "0" was given for negative attitudes and poor practices. A score of "1" was given for each correct answer associated with positive attitudes and good practices, meaning that the maximum score was 36. A scale was used to grade the healthcare workers according to their level of knowledge. A total score for a healthcare worker $\geq 75 \%$ was considered "good", between 50 and $74 \%$ "moderate" and $50 \%$ "Insufficient".

Hand hygiene compliance was assessed based on practice, using an observation chart that covered: i) the type of healthcare requiring hand hygiene; ii) the type of hand hygiene applied; iii) the procedure for washing hands with soap and water; iv) the factors associated with the "standard precautions" for hand washing; v) the opportunities and vi) the actions based on the WHO's five moments for hand hygiene. A "compliance rate" for each healthcare worker was calculated by comparing the number of actions carried out for each type of care that required hand hygiene and the number of opportunities.

\section{Variables}

The dependent variable was hand hygiene compliance among healthcare workers working in one of the five buildings of the Aplahoue district hospital, expressed as the "compliance rate". The independent variables were associated with:

Socio-demographic characteristics and background; age, sex, occupational category, seniority in the profession, soap allergies.

The healthcare worker's training: hand hygiene capacity building in the last 3 years (Yes/No), hospital-acquired infections capacity building in the last 3 years (Yes/No), knowledge of hospital-acquired infections from basic training (Yes/No), knowledge of hand hygiene in hospital settings from basic training (Yes/No).

The healthcare worker's level of hand hygiene knowledge (good/moderate/poor).

The healthcare worker's application of standard precautions for the prevention and control of infections: wearing short-sleeved scrubs (Yes/No), wearing hand jewellery (Yes/No), wearing watches (Yes/No), wearing bracelets (Yes/No), short fingernails (Yes/ No), artificial fingernails (Yes/No), unvarnished fingernails (Yes/No). 


\section{Data Processing and Statistical Analysis}

The data was entered using the software Epi Info version 7, and analysed using Stata 11. Proportion comparisons were conducted using the chi-square test. For the search for links between hand hygiene compliance and factors associated with the healthcare workers, a univariate analysis of the data by simple linear regression was conducted using the Fisher statistical test with a p-value considered significant at a threshold of $5 \%$.

\section{Results}

\section{Description of the Sample}

In total, 59 healthcare workers with a median age of 38 (30-42) participated in the study, of which 38 (64.4\%) were women and 25 (42\%) auxiliary nurses (Table 1$)$.

\begin{tabular}{|c|c|c|}
\hline \multirow[b]{2}{*}{ Characteristics } & \multirow[b]{2}{*}{ Number } & \multirow[b]{2}{*}{$\%$} \\
\hline & & \\
\hline \multicolumn{3}{|l|}{ Sex } \\
\hline Female & 38 & 64.4 \\
\hline Mal & 21 & 35.6 \\
\hline \multicolumn{3}{|l|}{ Professional category } \\
\hline Doctors & 4 & 6.8 \\
\hline Nurse & 20 & 33.9 \\
\hline Midwives & 4 & 6.8 \\
\hline Laboratory technicians & 5 & 8.5 \\
\hline Nurse Anesthetist-Reanimators & 1 & 1.7 \\
\hline Carers & 25 & 42.4 \\
\hline \multicolumn{3}{|l|}{ Seniority in the profession } \\
\hline$<1$ year & 1 & 1.7 \\
\hline 1 year & 2 & 3.4 \\
\hline 2 years & 1 & 1.7 \\
\hline 3 years & 3 & 5.1 \\
\hline$>3$ years & 52 & 88.1 \\
\hline \multicolumn{2}{|l|}{ Capacity building on hand hygiene } & \\
\hline No & 51 & 86.4 \\
\hline Yes & 8 & 13.6 \\
\hline Capacity building on IN * & & \\
\hline No & 53 & 89.8 \\
\hline Yes & 6 & 10.2 \\
\hline
\end{tabular}

\section{Level of Hand Hygiene and Hospital-Acquired Infection Knowledge among Healthcare Workers}

$76.3 \%$ of the healthcare workers have a moderate knowledge of hand hygiene (Table 2), 62.7\% know the main way germs are spread between patients in a healthcare facility, and $93.2 \%$ know the components of hand hygiene.

\begin{tabular}{|c|c|}
\hline Knowledge level & \% \\
\hline Good & 23.7 \\
\hline Moderate & $\mathbf{7 6 . 3}$ \\
\hline Poor & 0.0 \\
\hline
\end{tabular}

Table 2: Level of knowledge on hand hygiene, Aplahoué Hospital $(\mathrm{n}=59)$

\section{Hand Hygiene Compliance}

The healthcare workers were observed for 30 to 60 minutes as they delivered care or services, excluding major emergency situations. Out of the 963 opportunities counted, 117 actions were recorded during the provision of the healthcare or service and all involved simple washing with soap and water, giving an overall compliance rate of $12.15 \%$. It varies significantly according to the World Health Organisation's five indications between $2.1 \%$ prior to touching the patient and $50 \%$ in cases of exposure to a biological fluid $(\mathrm{p}<0.000)$ (Figure 1). This rate also varies significantly according to the department of activity, with a higher compliance rate in the laboratory ( $\mathrm{p}$-value $=0.008)$ in relation to the general medicine department. 


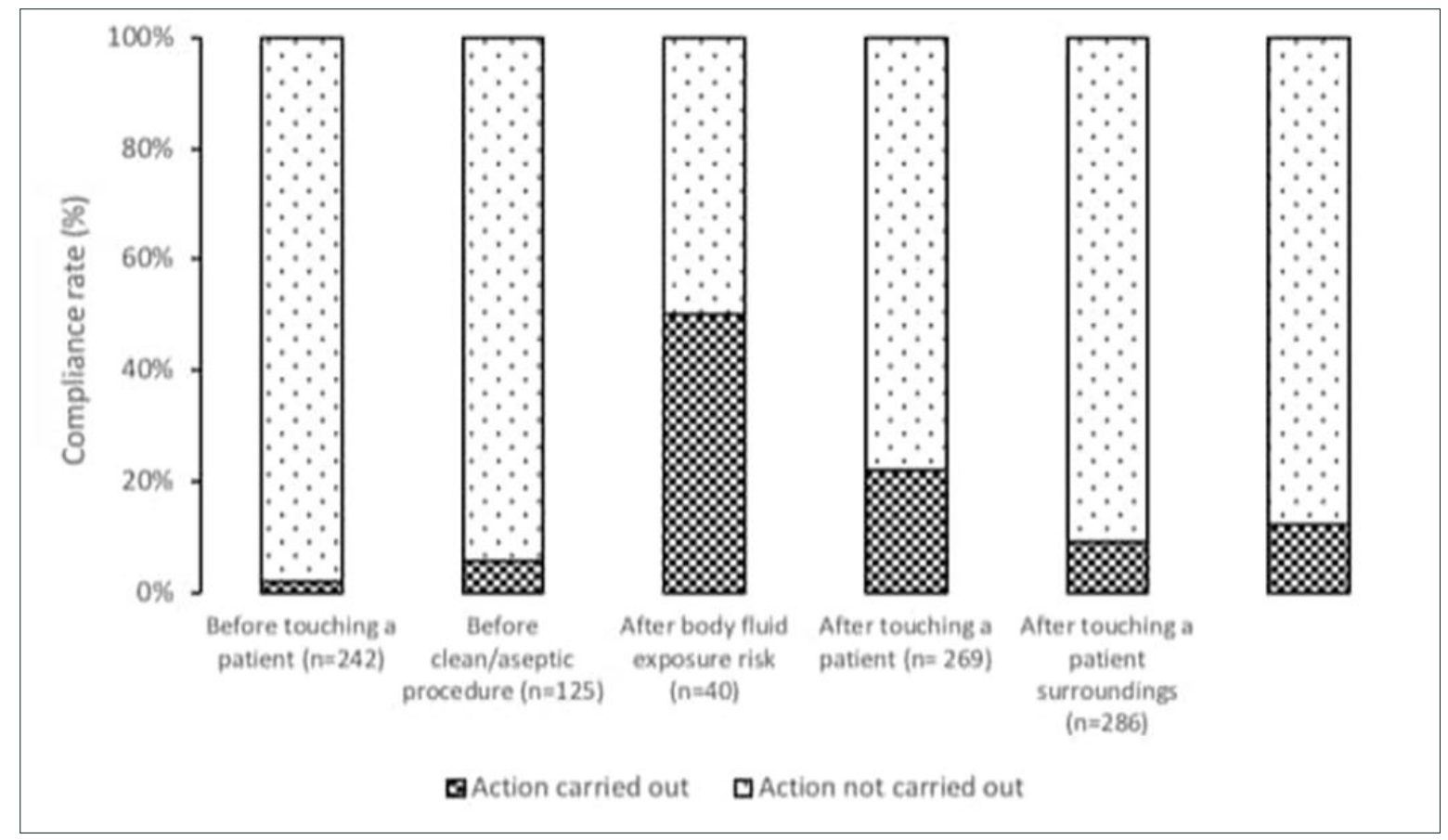

Figure 1: Hand hygiene compliance among healthcare workers according to five World Health Organization's indication

The individual hand hygiene compliance rate among the healthcare workers at the Aplahoue district hospital varies between $0 \%$ and $40 \%$.

The factors related to health professionals associated with hand hygiene compliance were knowledge of hospital-acquired infections from basic training (coefficient $=8.86$ and p-value $=0.000$ ), knowledge of hand hygiene in hospital settings from basic training (coefficient $=8.25$ and $\mathrm{p}$-value $=0.001)$, soap allergies (coefficient $=-5.46$ and $\mathrm{p}$-value $=0.041$ ), and occupational category $(\mathrm{p}$-value $<0.05)$ (Table 3a).

\begin{tabular}{|c|c|c|c|}
\hline Independent variables & coefficients & $\mathrm{CI}_{95 \%}$ & p-value \\
\hline \multicolumn{4}{|c|}{ Sex } \\
\hline Male & 1 & & - \\
\hline Female & 0.28 & {$[-5.10-5.65]$} & 0.918 \\
\hline Age & 0.06 & {$[-0.27-0.39]$} & 0.709 \\
\hline \multicolumn{4}{|c|}{ Occupational category } \\
\hline Nurses & 1 & & - \\
\hline Physicians & 5.55 & {$[-3.41-14.51]$} & 0.219 \\
\hline Midwives & 11.97 & [3.01-20.93] & $0.010^{*}$ \\
\hline Midwives & 14.75 & [6.58-22.94] & $0.001^{*}$ \\
\hline Nurse anesthetists & 20.88 & {$[4.12-37.65]$} & $0.016^{*}$ \\
\hline Auxiliary nurses & -1.63 & {$[-6.54-3.28]$} & 0.508 \\
\hline \multicolumn{4}{|c|}{ Seniority in the profession (years) } \\
\hline$>3$ & 1 & & - \\
\hline 1 & 1.70 & {$[-12.49-15.88]$} & 0.812 \\
\hline 2 & 14.74 & {$[-5.14-34.62]$} & 0.143 \\
\hline 3 & 6.65 & {$[-5.14-18.24]$} & 0.266 \\
\hline$<1$ & 4.92 & {$[-14.96-24.80]$} & 0.622 \\
\hline
\end{tabular}

Regarding the factors related to health professionals in relation to the standard precautions related to the rate of compliance of hand hygiene, only the wearing short-sleeved scrubs (coefficient $=9.82$ and p-value $=0.011)($ Table $3 b)$. 


\begin{tabular}{|c|c|c|c|}
\hline Independent variables & coefficients & $\mathrm{CI}_{95 \%}$ & P-value \\
\hline \multicolumn{4}{|c|}{ Hand hygiene capacity building in the last 3 years } \\
\hline Yes & 1 & & - \\
\hline No & -4.74 & {$[-12.15-2.67]$} & 0.205 \\
\hline \multicolumn{4}{|c|}{$\begin{array}{l}\text { Hospital-acquired infections capacity building in the last } 3 \\
\text { years }\end{array}$} \\
\hline Yes & 1 & & - \\
\hline No & -6.80 & {$[-15.12-1.52]$} & 0.107 \\
\hline \multicolumn{4}{|c|}{ Knowledge of hospital-acquired infections from basic training } \\
\hline Yes & 1 & & - \\
\hline No & -8.86 & {$[-13.54--4.18]$} & $0.000^{*}$ \\
\hline \multicolumn{4}{|c|}{$\begin{array}{c}\text { Knowledge of hand hygiene in hospital settings from basic } \\
\text { training }\end{array}$} \\
\hline Yes & 1 & & - \\
\hline No & -8.25 & {$[-13.05--3.45]$} & $0.001^{*}$ \\
\hline \multicolumn{4}{|c|}{ Current level of knowledge on hand hygiene } \\
\hline Good & 1 & & - \\
\hline Moderate & 11.19 & {$[-8.58-30.96]$} & 0.262 \\
\hline Poor & 2.55 & {$[-25.17-30.26]$} & 0.855 \\
\hline \multicolumn{4}{|c|}{ Soap allergies } \\
\hline Yes & 1 & & - \\
\hline No & 5.46 & {$[0.22-10.70]$} & $0.041^{\star}$ \\
\hline
\end{tabular}

\section{Discussion}

This study conducted on 59 healthcare workers provides a point-in-time analysis of the situation. It highlights the issue of hand hygiene knowledge and compliance in our hospitals.

The proportion of healthcare workers with a "good" level of awareness, 23.73\% (14/59), is higher than the 9\% (13/144) found in India by Nair SS et al. [7]. This difference can be explained by the difference in the occupational category of those surveyed. Nair SS et al. conducted their study among medical and nursing students. The proportion of healthcare workers who knew the components of hand hygiene were $93.22 \%$, compared with the $0 \%$ found by Hien $\mathrm{H}$ et al. in their study in Burkina Faso in 2013 [8]. This difference can be explained by the techniques used to collect the data from the healthcare workers in our different studies. Those who know the main way germs are spread between patients in a healthcare facility represented $62.71 \%$ in our study, and a score of $44.6 \%$ in the study by Hien $\mathrm{H}$ et al., but these scores were still lower than the $73.61 \%$ found by Nair SS et al. $[7,8]$. The overall hand hygiene compliance rate among healthcare workers delivering healthcare and services in the Aplahoue district hospital was very low in 2017. The overall hand hygiene observance rate found by Hien $\mathrm{H}$ et al., in their study conducted in Burkina Faso 2013, was lower at 36.85\% [8]. It was 37.00\% in the study in Istanbul by Karaaslan A et al. in 2014 [9]. The fact that "auxiliary nurses" made up $42.37 \%$ of the sample in our study may explain the low rate of hand hygiene compliance compared with the studies by Karaaslan A et al. in 2014 (37.00\%) and Hien H et al. in 2013 (36.85\%). Due to the quality of their professional training, auxiliary nurses may have less knowledge concerning hygiene before and after providing healthcare; as a consequence, they need more support with hand hygiene practices and compliance in hospital settings than those from other occupational categories. The overall hand hygiene compliance rate found by Uneke CJ et al. in their study on the promotion of hand hygiene in 2014 in Nigeria was six (06) times higher than that found in our study, in other words $65.3 \%$ [10]. This high rate in Nigeria is warranted as the study was divided into two phases: an intervention phase (training for doctors and nurses, use of reminders concerning hand hygiene in the form of posters in strategic places around the hospital, and the provision of bottles of 70\% alcohol isopropyl) and an evaluation phase two months after the intervention. It is normal therefore that there should be an improvement in hand hygiene compliance. The 50\% compliance rate after exposure to a biological fluid in our study was higher than that found by Karaaslan A et al. (18.10\%) in their study conducted in Istanbul in 2014 [9]. Our study revealed compliance rates of 2.07\% "before touching a patient" and $21.93 \%$ "after touching a patient"; these results were lower than those obtained by Diarra F in Benin in 2007: 67.1\% and 91.2\% before and after the medical intervention respectively [11]. This study was conducted on 362 healthcare workers at Cotonou hospital, a referral hospital with an operational hospital hygiene department and which therefore supports and supervises staff in the area of hospital hygiene on a day-to-day basis; which is not the case at the Aplahoue district hospital. The setting of the study would therefore explain this difference. 
In this study, the factors associated with the hand hygiene compliance rate were identified. As such, there is a significant link between the overall hand hygiene compliance rate and knowledge of hospital-acquired infections from basic training. The average overall hand hygiene compliance rate is lower (by approximately 8.86\%) among healthcare workers who do not have knowledge of hospital-acquired infections from their basic training in relation to the average overall hand hygiene compliance rate among healthcare workers who do have knowledge of hospital-acquired infections from their basic training. Likewise, there is a significant link between the overall hand hygiene compliance rate and knowledge of hand hygiene in hospital settings from basic training. The average overall hand hygiene compliance rate is lower (by approximately $8.25 \%$ ) among healthcare workers who do not have knowledge of hand hygiene in hospital settings from their basic training in relation to the average overall hand hygiene compliance rate among healthcare workers who do have knowledge of hand hygiene in hospital settings from their basic training. It is therefore important to introduce teaching on hospital-acquired infections and hospital hygiene in basic training courses in the country's schools and faculties in the health sciences sector.

As regards soap allergies, there is a significant link between the overall hand hygiene compliance rate and soap allergies. Indeed, the average overall hand hygiene compliance rate is higher (by approximately 5.46\%) among healthcare workers who are not allergic to soap in relation to the average overall hand hygiene compliance rate among professionals who are allergic to soap. Hydro-alcohol rubbing is a valid alternative that should be considered.

As regards compliance with standard precautions recommended to prevent hospital-acquired infections, there is a significant link between the overall hand hygiene compliance rate and the wearing of short-sleeved scrubs. The average overall hand hygiene compliance rate is in fact higher (by approximately 9.82\%) among healthcare workers who wear short-sleeved scrubs in relation to the average overall hand hygiene compliance rate among healthcare workers who do not wear short-sleeved scrubs (Table 4).

\begin{tabular}{|c|c|c|c|}
\hline Independent variables & coefficients & $\mathrm{CI}_{95 \%}$ & p-value \\
\hline \multicolumn{4}{|c|}{ Wearing short-sleeved scrubs } \\
\hline No & 1 & & - \\
\hline Yes & 9.82 & {$[2.30-17.34]$} & $0.011^{*}$ \\
\hline \multicolumn{4}{|l|}{ Wearing hand jewellery } \\
\hline No & 1 & & - \\
\hline Yes & 2.25 & {$[-7.97-12.47]$} & 0.661 \\
\hline \multicolumn{4}{|l|}{ Wearing watches } \\
\hline No & 1 & & - \\
\hline Yes & -4.17 & {$[-18.35-10.00]$} & 0.558 \\
\hline \multicolumn{4}{|l|}{ Wearing bracelets } \\
\hline No & 1 & & - \\
\hline Yes & -6.19 & {$[-17.78-5.41]$} & 0.290 \\
\hline \multicolumn{4}{|l|}{ Short fingernails } \\
\hline Yes & 1 & & - \\
\hline No & 1.52 & {$[-6.43-9.47]$} & 0.703 \\
\hline \multicolumn{4}{|l|}{ Artificial fingernails } \\
\hline No & 1 & & - \\
\hline Yes & 0.39 & {$[-13.83-14.61]$} & 0.957 \\
\hline \multicolumn{4}{|l|}{ Short fingernails } \\
\hline Yes & 1 & & - \\
\hline No & -3.07 & {$[-17.26-11.13]$} & 0.667 \\
\hline
\end{tabular}

Although not found as factors associated with the low rate of hand hygiene compliance in this study, capacity building on hospitalacquired infections in the last 3 years and on hand hygiene in hospital settings in the last 3 years, and current training remain major factors in the strategy to promote hand hygiene in hospital settings [12].

After the study, there were recommendations that have already been made in the direction of the hospital on the in-service training in hospital hygiene of the nursing staff and posters of communication for a change of behaviour and the use almost permanent $70 \%$ alcohol for hand rub.

Similar studies should be undertaken at the level of two health departments expanding the study framework by including at least three zone hospitals. These studies may identify other factors that may be associated with observance of hand hygiene in hospitals. 


\section{Limitations of the Study}

The non-probabilistic method, the exhaustiveness technique and the small sample size could not make it possible to generalize the results obtained to all health facilities in the region.

\section{Conclusion}

Our study shows the factors that determine the hand hygiene compliance rate. These are: knowledge of hospital-acquired infections, and knowledge of hand hygiene in hospital settings from basic training. The wearing of short-sleeved scrubs, soap allergies and occupational category are also factors associated with hand hygiene compliance. The current level of knowledge of hand hygiene among healthcare workers is acceptable. The overall hand hygiene compliance rate remains low (12.15\%). A multimodal strategy should be undertaken to increase this rate and help improve hospital hygiene in the Aplahoue district hospital.

\section{Competing Interests}

All authors report no conflicts of interest relevant to this article.

\section{Acknowledgements}

The authors thank all the health professionals of the CHUD-O / P neonatology department for their contribution to the realization of this study. Thanks also go to all CAP/EPAC-UAC staff for all their contribution to the initiation and conduct of this training.

\section{References}

1. WHO (2010) Hand Hygiene: Technical Reference Manual: for healthcare professionals, trainers and observers of hand hygiene practices, Geneva

2. Pittet D, Allegranzi B, Storr J, Donaldson L (2006) The Global Patient Safety, Challenge 2005-2006 “Clean Care is Safer Care". International of Infectious Diseases 10: $419-24$.

3. El Rhazi K, Elfakir S, Berraho M, Tachfouti N, Serhier Z, et al. (2007) Prévalence et facteurs de risque des infections nosocomiales au CHU Hassan II de Fès (Maroc). Revue de la Santé de la Méditerranée Orientale 13: 56-63.

4. Biaou G (2011) Infections du site opératoire dans les services de chirurgie viscérale A \&B du CNHU-HKM. Thèse de médecine, Faculté des Sciences de la Santé Cotonou : Université d'Abomey-Calavi Bénin

5. Dégbey C, Aguèmon B, Ouendo E-M, Makoutodé M, Simon A (2013) Study of the quality of medico-technical equipment used in operating theaters for the prevention of infections associated with care and services at the National Hospital and University Center of Cotonou - Benin. Journal of the Society of Clinical Biology 018: 29-35.

6. Pittet D (2009) Hygiene des mains : révolution, normalisation, globalisation, Rev Med Suisse 5: 716-21.

7. Nair SS, Hanumantappa R, Hiremath SG, Siraj MA, Raghunath P (2014) Knowledge, Attitude, and Practice of Hand Hygiene among Medical and Nursing Students at a Tertiary Health Care Centre in Raichur, India. ISRN Prev Med: ID 608927.

8. Hien H, Drabo M, Ouédraogo L, Konfé S, Sanou D, et al. (2013) Knowledge and practices of health professionals on the infectious risk associated with care: study in a district hospital in Burkina Faso. Public health 25: 219-26.

9. Karaaslan A, KepenekliKadayifci E, Atici S, Sili U, Soysal A, et al. (2014) Compliance of healthcare workers with hand hygiene practices in neonatal and pediatric intensive care units: overt observation. Interdiscip Perspect Infect Dis 2014: 306478.

10. Uneke CJ, Ndukwe CD, Oyibo PG, Nwakpu KO, Nnabu RC, et al. (2014) Promotion of hand hygiene strengthening initiative in a Nigerian teaching hospital: implication for improved patient safety in low-income health facilities. Braz J Infect Dis 18: 217.

11. Diarra F (2007) Evaluation of hand washing practices at the staff of the Hubert Kotuku MAGA National Hospital and University Center in Cotonou. Master's thesis in public health, IRSP: University of Abomey-Calavi, Bénin.

12. Allegranzi B, Gayet-Ageron A, Damani N, Bengaly L, McLaws ML, et al. (2013) Global implementation of WHO's multimodal strategy for improvement of hand hygiene: a quasi-experimental study. The Lancet Infectious Diseases 13: 843-51.

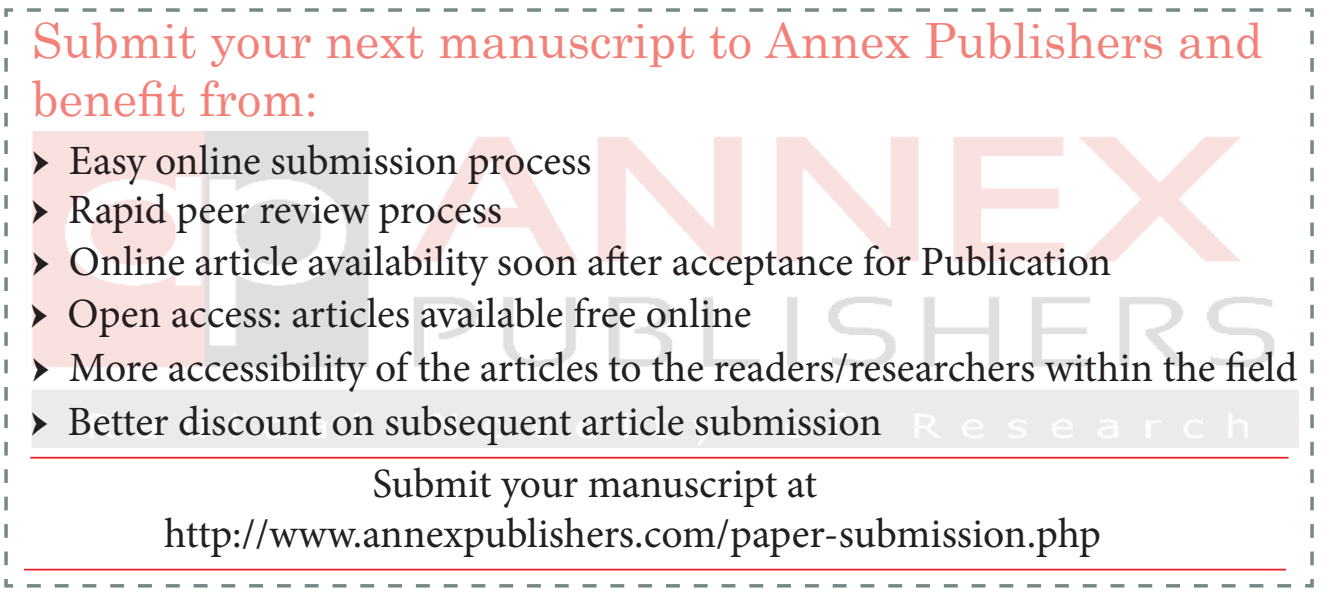

